\title{
A Field Study on the Indoor Thermal Environment of the Airport Terminal in Tibet Plateau in Winter
}

\author{
Jianglong Zhen, ${ }^{1}$ Jun Lu, ${ }^{2}$ Guangqin Huang, ${ }^{1}$ Liyue Zeng, ${ }^{2}$ Jianping Lin, ${ }^{3}$ and Hongtao Xia ${ }^{3}$ \\ ${ }^{1}$ Department of Defense Architectural Planning and Environmental Engineering, Logistical Engineering University, \\ Chongqing 401311, China \\ ${ }^{2}$ Key Laboratory of Three Gorges Reservoir Region's Eco-Environment, Ministry of Education, Chongqing University, \\ Chongqing 400045, China \\ ${ }^{3}$ Southwest Branch of China Airport Construction Group Corporation, Chengdu 610202, China \\ Correspondence should be addressed to Jun Lu; lujun66@vip.sina.com
}

Received 10 December 2016; Accepted 1 February 2017; Published 2 April 2017

Academic Editor: Yanxia Du

Copyright (C) 2017 Jianglong Zhen et al. This is an open access article distributed under the Creative Commons Attribution License, which permits unrestricted use, distribution, and reproduction in any medium, provided the original work is properly cited.

In order to study the characteristics of indoor thermal environment in the airport terminal in Tibet Plateau with radiant floor heating in winter, a field measurement of the indoor thermal environment was conducted in Lhasa Gonggar Airport terminal 2. First, the unique climate characteristics in Tibet Plateau were analyzed through comparison of meteorological parameters in Beijing and Lahsa. The thermal environment in the terminal was divided into outer zone and inner zone as well as south zone and north zone. Thermal environment parameters including air temperature, black globe temperature, relative humidity in each zone, and inner surface temperature of envelope were measured and analyzed. Meanwhile, temperature and relative humidity in the vertical direction were measured. In addition, PMV and PPD were calculated for evaluating the thermal environment in the terminal. The findings can provide guidance for the design and regulation of thermal environment in terminals in Tibet Plateau in China.

\section{Introduction}

The altitude of Tibet Plateau is basically above 3000 meters, leading to special climatic characteristics including lower air pressure, stronger solar radiation, higher atmospheric transparency, larger diurnal temperature range, and smaller annual temperature range. In addition to hypoxia, cold and dry climate in winter is another important factor to influence local residents. With the development of the western region, the local residents have an urgent need to improve the indoor thermal environment. However, with the influence of the unique climate, building thermal process and indoor thermal environment characteristics in Tibet Plateau are inevitably different from that in the plains. The relevant scholars have conducted a lot of researches on the indoor thermal environment in this region. Particularly, Liu's scientific research team, including Wang et al., carried out the field measurement of the indoor thermal environment of rural and urban residential buildings in Lhasa, using standard effective temperature (SET) and discomfort index (DISC) to evaluate it [1]. Meanwhile, they also studied the influence of different glass types and curtain on the thermal environment of the rooms facing north and south [2]. Besides, the heating performance of the sunspace with Trombe wall in QinghaiTibet Plateau was tested and analyzed, and the results showed that the energy saving rate of the sunspace was up to $72.8 \%$ [3]. Zhu et al. [4] corrected the correction factor of heat transfer coefficient of urban enclosure structure in Tibet. In addition, Huang and Leng [5] evaluated and analyzed the indoor thermal environment of traditional houses in Nyingchi in winter.

Terminals are buildings with large glass curtain wall. Therefore, the outdoor weather conditions, especially the solar radiation, have a great influence on the indoor thermal environment, and the distribution of indoor thermal environment is uneven and different from the conventional buildings. Numerous researchers around the world have conducted studies on the indoor environment of airport terminals. Balaras et al. [6] studied the energy consumption and indoor environment quality of Hellenic airport terminal 
TABLE 1: Climatic characteristics of Beijing and Lhasa in January.

\begin{tabular}{lccccccc}
\hline & $\begin{array}{c}\text { Atmospheric } \\
\text { pressure }(\mathrm{kPa})\end{array}$ & $\begin{array}{c}\text { Total radiation } \\
\left(\mathrm{MJ} /\left(\mathrm{m}^{2}\right)\right)\end{array}$ & $\begin{array}{c}\text { Sunshine } \\
\text { percentage }\end{array}$ & $\begin{array}{c}\text { Average ambient } \\
\text { temperature }\left({ }^{\circ} \mathrm{C}\right)\end{array}$ & $\begin{array}{c}\text { Diurnal temperature } \\
\text { difference }\left({ }^{\circ} \mathrm{C}\right)\end{array}$ & $\begin{array}{c}\text { Heating days } \\
(\text { day })\end{array}$ & $\begin{array}{c}\text { Atmospheric } \\
\text { transparency }\end{array}$ \\
\hline Beijing & 100.8 & 253.4 & $68 \%$ & -3.8 & 8.9 & 122 & 4 \\
Lhasa & 64.4 & 491.9 & $78 \%$ & -1.5 & 13.4 & 136 & 1 \\
\hline
\end{tabular}

buildings in different climate in 2003 through objective and subjective observation. The result showed that there were significant differences at various spaces of the terminal. Kotopouleas and Nikolopoulou [7] investigated the indoor thermal environment of three airport terminal buildings in the UK. It was found that overheating existed during summer and winter and the thermal sensation levels of travelers were different from that of staff. In addition, the indoor thermal comfort levels of three major Brazilian airports were evaluated by Ramis and Santos [8] through on-site measurement. Wang et al. [9] investigated the indoor environment quality of eight major Chinese large-hub airport terminal buildings through instrumental objective measurements and questionnaire subjective surveys. Instrumental measurements showed that the black globe temperature in departure lounge was averagely $3-5^{\circ} \mathrm{C}$ higher than air temperature due to large external glazing. However, there are few studies on the indoor thermal environment of terminals in Tibet Plateau.

\section{Climatic Characteristics of Tibet Plateau}

Lhasa, one of the cities with the highest altitude in the world, is located at $91^{\circ} 06^{\prime}$ east longitude and $29^{\circ} 36^{\prime}$ north latitude, that is, the middle of the Qinghai-Tibet Plateau at an altitude of $3658 \mathrm{~m}$, where the climate is dryer, with thinner air, dust, less water vapor, and higher atmospheric transparency [10]. Therefore, the solar radiation is stronger and the annual average sunshine time is $3005 \mathrm{~h}$, with the total solar radiation of $8160 \mathrm{MJ} / \mathrm{m}^{2}$. It is called "City of Sunlight" [11]. In winter, the daytime temperature is above $0^{\circ} \mathrm{C}$, basically up to $6 \sim 7^{\circ} \mathrm{C}$ in January, while the lowest temperature at night is about $-11 \sim-12^{\circ} \mathrm{C}$. The daily average temperature is $6^{\circ} \mathrm{C}$. The diurnal range of temperature is up to $15^{\circ} \mathrm{C}$, while the annual range is only $17.7^{\circ} \mathrm{C}[12]$.

In order to further analyze the climate difference between Tibet Plateau and the plains and highlight the unique climate characteristics in the plateau area, meteorological data in a typical day in Beijing and Lhasa in January from "China construction standard meteorological database" is compared, as shown in Figure 1. According to the climate division for building thermal, Beijing and Lhasa are both in cold area. The altitude of Beijing is $44.4 \mathrm{~m}$, while that of Lhasa is $3658 \mathrm{~m}$.

As is shown in Table 1, the difference of the average ambient temperature between Lhasa and Beijing in January is not great, while the diurnal temperature difference in Lhasa is much larger than that in Beijing. As is shown in Figure 1(a), the difference of ambient temperature between Lhasa and Beijing at night is not great, and the lowest temperature in Lhasa is lower than that in Beijing. However, the daytime temperature of Lhasa is much higher than that of Beijing. The reason is that, due to the higher atmospheric transparency in Lhasa, the sky background temperature at night is much lower, but the solar radiation during the day is stronger, resulting in its greater temperature gap between day and night. Figure 1(b) indicates that the diffuse solar radiation in Lhasa is similar to that in Beijing, while its direct solar radiation is much higher than that in Beijing, causing the total solar radiation to be much higher than that in Beijing. The former's total solar radiation in January is almost twice as much as the latter, and Lhasa's sunshine lasts for a long time. In addition, the relative humidity in Lhasa is lower than that in Beijing, as shown in Figure 1(c), indicating the dryer air and higher atmospheric transparency in the region. In terms of wind speed, in Lhasa, it greatly changes throughout the day, and generally after the afternoon, it will be windy, as illustrated in Figure 1(d), while the wind speed in Beijing is stable, at about $2.4 \mathrm{~m} / \mathrm{s}$. According to the atmospheric transparency classification by "standards of heating, ventilation, and air conditioning design for civil buildings," atmospheric transparency in Lhasa is significantly higher than that in Beijing, which will inevitably make the sky background temperature lower. Therefore, the heat loss caused by the long-wave radiation of building envelope to the sky is greater. As a result, the climate in the highaltitude and cold region is obviously different from that in the plains, and its remarkable characteristic is lower air pressure, stronger solar radiation, greater temperature difference between day and night, lower relative humidity, higher atmospheric transparency, longer heating period, and so forth.

\section{Field Measurement}

3.1. Description of the Airport Terminal. Lhasa Gonggar Airport ( $3600 \mathrm{~m}$ elevation) is located in Gonggar Town of Jiazhulin County, Tibet Autonomous Region, and on the south bank of the beautiful Yarlung Zangbo River. Terminal 2 is its latest building, as shown in Figure 2, whose main space is made up of the check-in hall on the first floor and departure hall on the second floor. The building envelope is mainly glass curtain wall, with the visible light transmission rate of 0.39 , the heat transfer coefficient of $2.3 \mathrm{~W} /\left(\mathrm{m}^{2} \cdot \mathrm{K}\right)$, and the shading coefficient of 0.3 . The daylighting band made of polycarbonate with heat transfer coefficient of $2.7 \mathrm{~W} /\left(\mathrm{m}^{2} \cdot \mathrm{K}\right)$ and shading coefficient of 0.4 accounts for $10 \%$ of the roof, and the rest is composed of the aluminum alloy plate with the heat transfer coefficient of $0.55 \mathrm{~W} /\left(\mathrm{m}^{2} \cdot \mathrm{K}\right)$.

A central air conditioning system is adopted for the regulation of the indoor thermal environment in the terminal. Horizontal combined air-conditioner units are used for the regulation of the thermal environment in the check-in hall on the first floor. Parts of supply-air outlets and all the return 


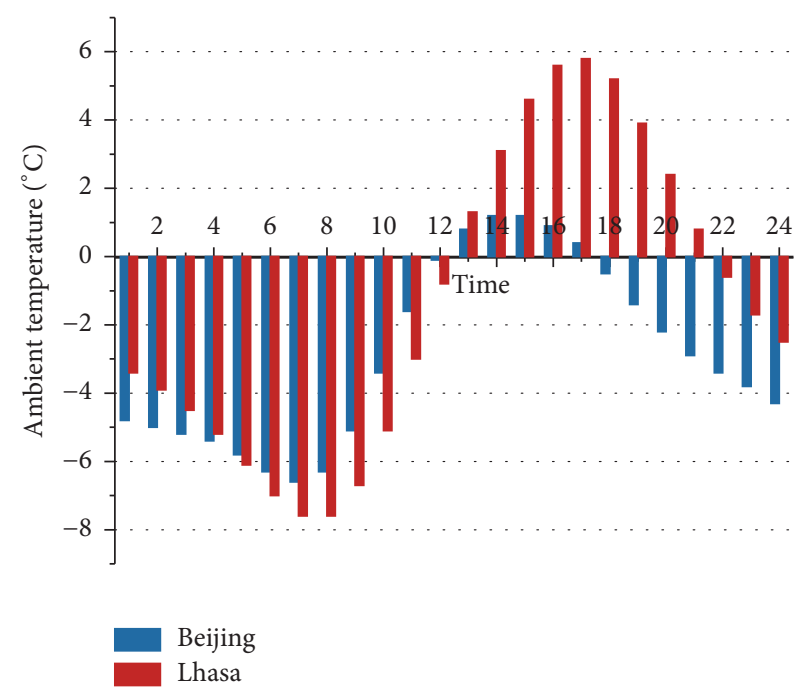

(a)



(c)
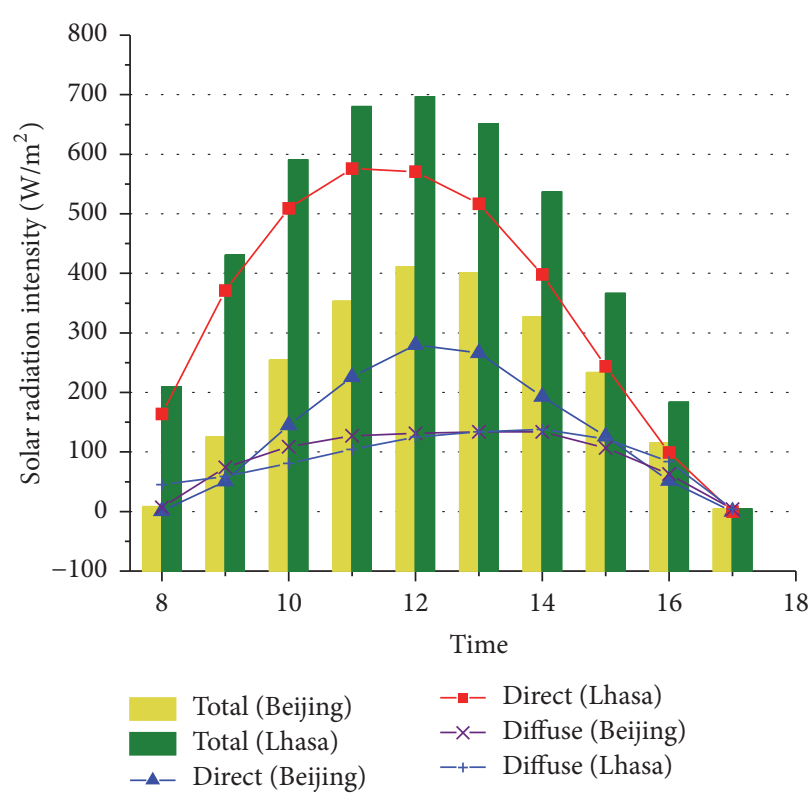

(b)

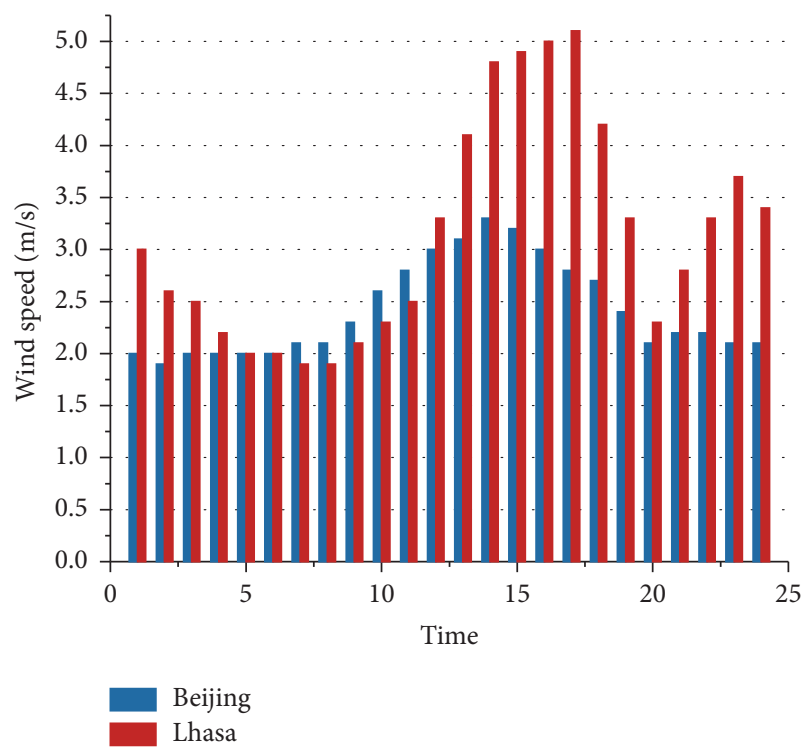

(d)

FIGURE 1: Comparison of the outdoor climate condition between Beijing and Lhasa in the typical day in January. (a) Temperature; (b) solar radiation; (c) relative humidity; (d) wind speed.
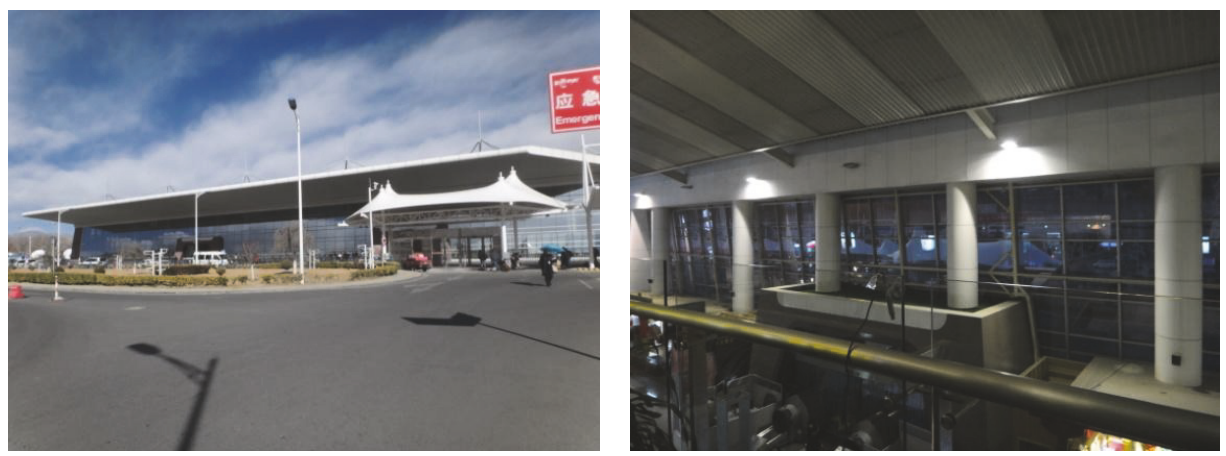

FIGURE 2: Lhasa Gonggar Airport. 


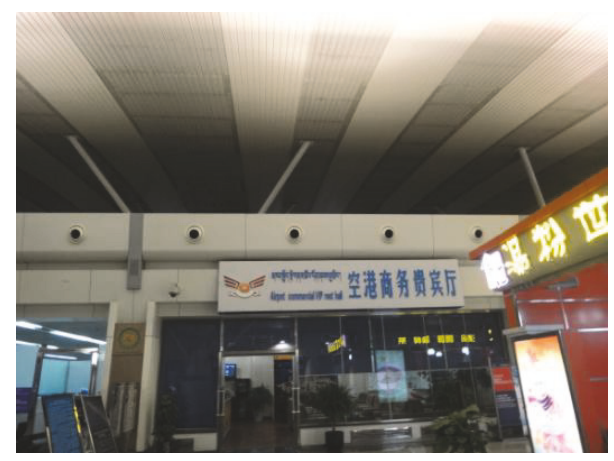

FIGURE 3: Ejector nozzle air supply outlets in the departure hall.

air inlets are in the ceiling, while other supply-air outlets are at the side of the terminal. Square diffusers are used as supplyair outlets, which are in the ceiling with a distance of $4 \mathrm{~m}$ between each other.

Stratified air conditioning mode with ejector nozzle air supply outlets is adopted to regulate the space within $4 \mathrm{~m}$ above the floor of departure hall on the second floor, as shown in Figure 3. Air is supplied into the space by horizontal combined air conditioning boxes at the side of the terminal. In order to make the air flow downward, spherical adjustable remote nozzle with large induced ratio is used to supply air into the area of travelers, guaranteeing the uniformity of supply air, as well as the thermal comfort. Meanwhile, the return air inlets are at the bottom of the wall of the first-class departure hall and shops. In addition, the heat source comes from 4 sets of air source heat pump unit in the power station.

3.2. The Outline of Site Measurement. The indoor area near the glass facade is susceptible to the influence of the outdoor weather conditions (solar radiation, air temperature, etc.), while the thermal environment in the inner zone is relatively stable. In order to study the thermal environment in the inner and outer zones and compare the differences, this paper will define the zone within the distance of $3 \mathrm{~m}$ from the glass facade as outer zone, and the rest is the inner zone.

Measured parameters include outdoor meteorological parameters, the air temperature, relative humidity and black globe temperature in the outer and inner zone of the terminal, the temperature and relative humidity distribution on the vertical direction, and the inner surface temperature of building envelope. Total solar radiation meter was used to measure the solar radiation intensity on $45^{\circ}$ inclining plane facing south, while the ambient temperature (Ta) and relative humidity (RHa) were automatically recorded and stored by data logger every $5 \mathrm{~min}$, which was carefully sheltered to avoid exposure to direct sunlight throughout the measurement. Indoor measuring point layout is shown in Figure 4. A self-recording hygro-thermometer and black globe thermometer were used to measure the air temperature (ATo), relative humidity (RHo), and black globe temperature (BGTo) in the outer zone (south zone), likewise for the air temperature (ATi2), relative humidity (RHi2), and black globe temperature (BGTi2) in the inner zone on the second floor and the ones in the north zone, as shown in Figure 5.

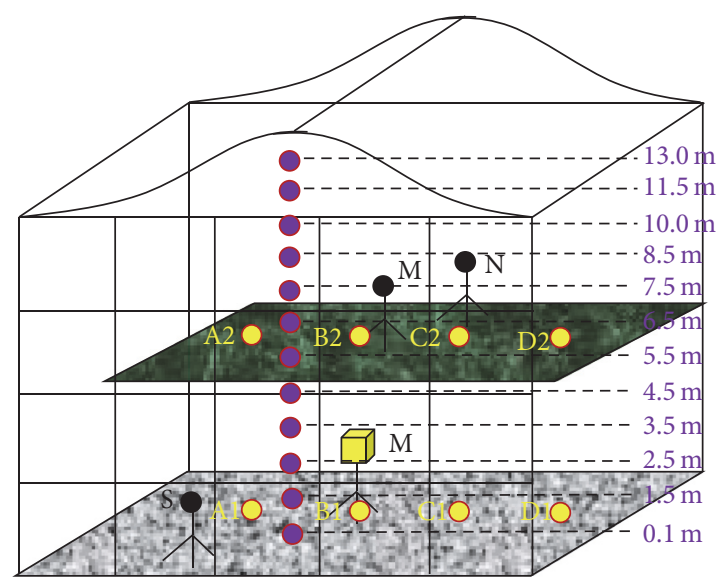

Figure 4: Measuring point layout.

The measuring points are, respectively, at points S, M2, and $\mathrm{N}$. A self-recording hygro-thermometer was used to measure the air temperature (ATil) and relative humidity (RHil) in the inner zone on the first floor, as point M1 in Figure 4. Twelve points are arranged on the vertical direction, with an intelligent temperature and relative humidity data logger recording their temperature and relative humidity. All the data were automatically recorded for 24 hours at a time interval of $5 \mathrm{~min}$. In addition, the inner surface temperature of building envelope was measured manually by a handheld infrared thermometer from 8:00 to 20:00 at a time interval of 1 hour. Four measuring points are selected on the central line of the ground on the first (G1) and second floor (G2), as points A1, B1, C1, and D1 and A2, B2, C2, and D2 in Figure 4, respectively, with their average temperature as the surface temperature of them.

The on-site test was conducted in January 23, 2015, when it was sunny. The test results are analyzed below.

\section{Results and Discussion}

4.1. Outdoor Meteorological Parameters. As is shown in Figure 6, the temperature difference between day and night in Lhasa in winter is larger, with dryer air and stronger solar radiation. Outdoor temperature changes within the range of $-8.64 \sim 7.66^{\circ} \mathrm{C}$, achieving the maximum and the minimum at $17: 30$ and 9:00, respectively, with the average of $-2.08^{\circ} \mathrm{C}$. The variation of relative humidity is contrary to it, within the range of $15.1 \% \sim 39.5 \%$, and the average value is $27.1 \%$. Solar radiation lasts from 9:00 to 19:00, with the maximum of $863 \mathrm{~W} / \mathrm{m}^{2}$ at 14:30. Thus, Lhasa is rich in solar energy, which has great application potential in heating.

\subsection{Comparison of the Thermal Environment in the Inner and} Outer Zones. Figure 7 indicates that the indoor temperature variation is consistent with the outdoor weather conditions. The variation of black globe temperature in the outer area is the greatest. The difference between black globe temperature and air temperature is far greater than that in the inner zone. The mean square error of the former one is up to 4.87 , while that of the latter is only 0.61 , which is mainly caused by solar 

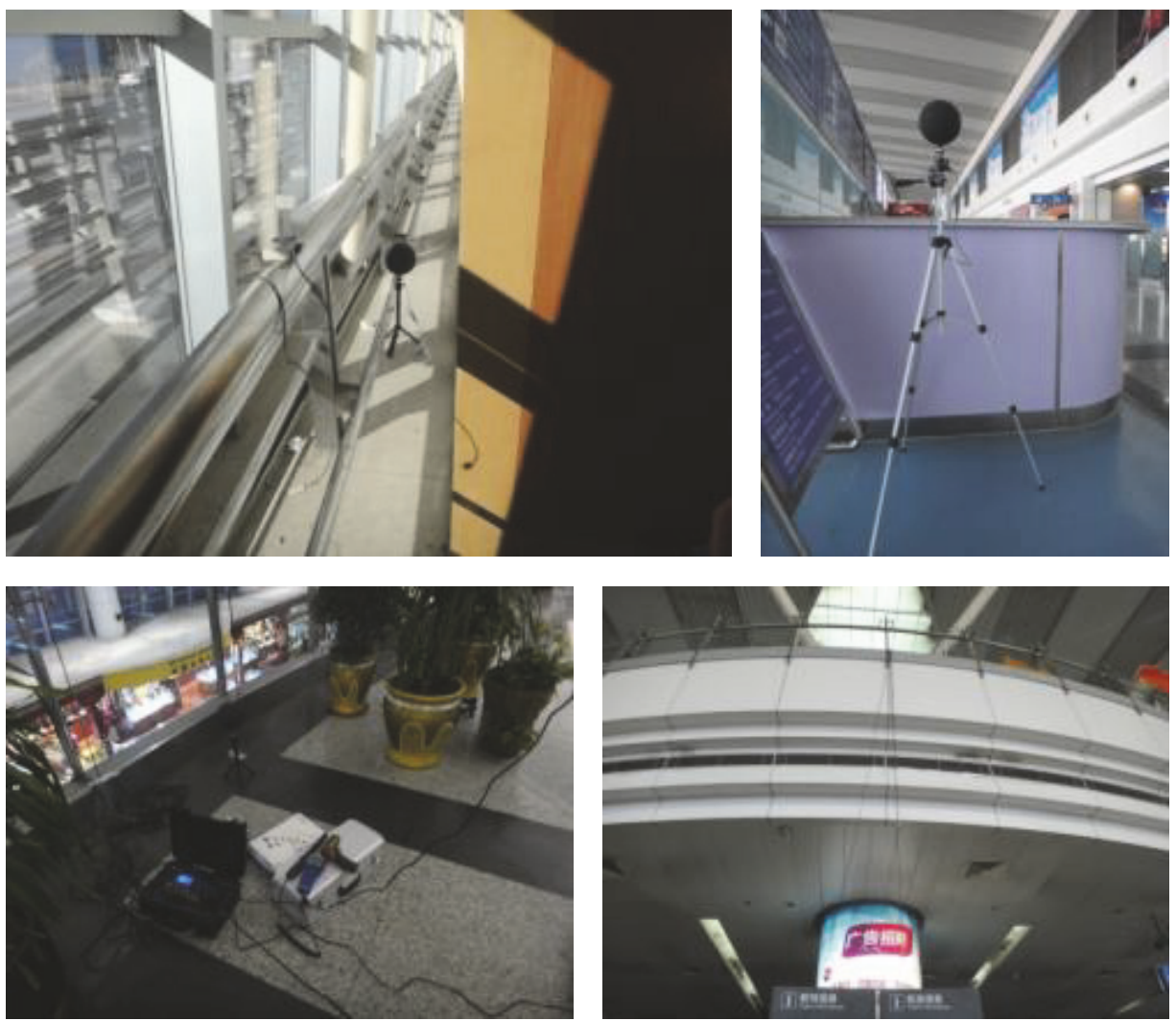

Figure 5: Test site.
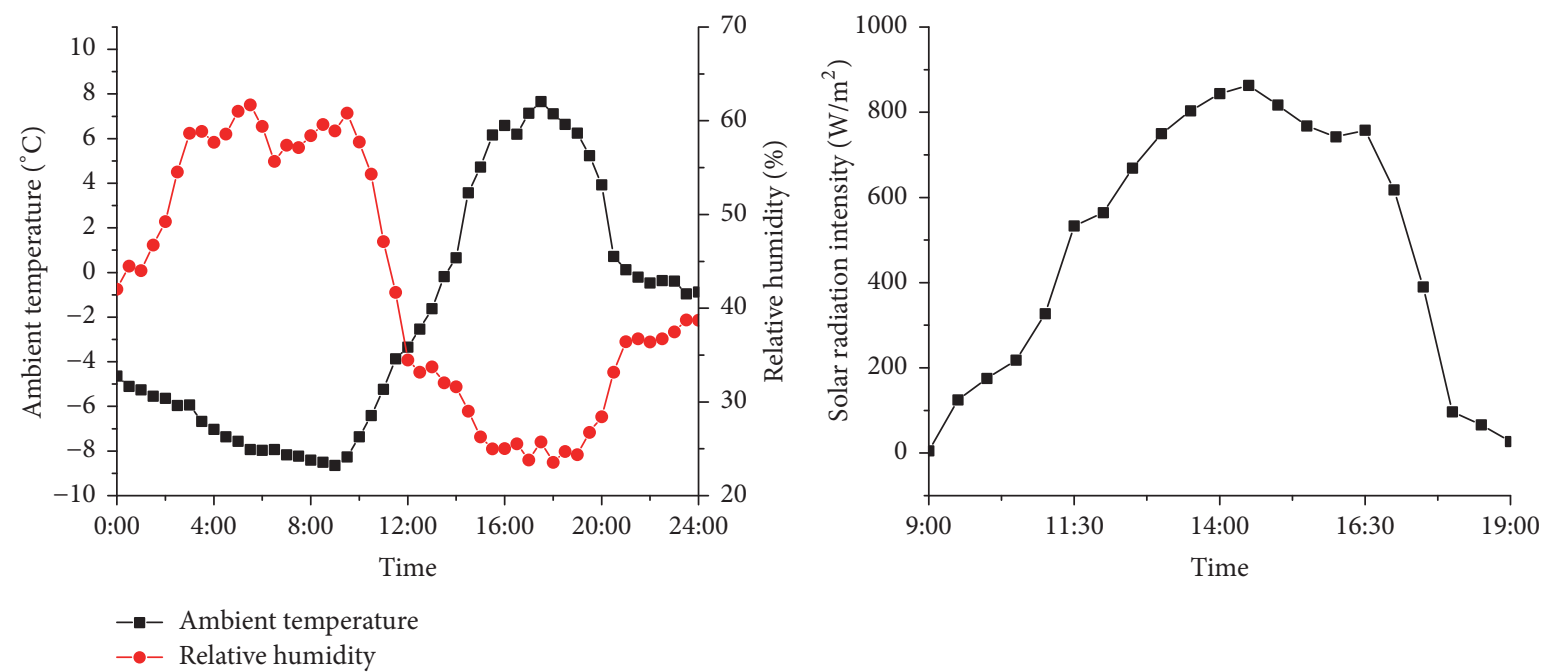

FIgURE 6: Outdoor meteorological conditions.

radiation, indicating that the effect of solar radiation on the thermal environment of the outer zone in the terminal is larger. Therefore, making full use of solar radiation for passive heating should be considered during the stage of architecture design. On the one hand, the inside part near the south glass facade should not have obstacles, in order to avoid the shelter against solar radiation. On the other hand, the terminal has the external shading, the size of which should be optimized.
In the meantime of reducing the cooling load in summer, the shading to solar radiation in winter should be reduced to the greatest degree. At the same time, the indoor ground should try to use the materials with larger absorption rate and the floor uses heavy material with larger heat capacity, in order to make full use of solar energy for heating and reduce the fluctuation of the indoor thermal environment as well. 

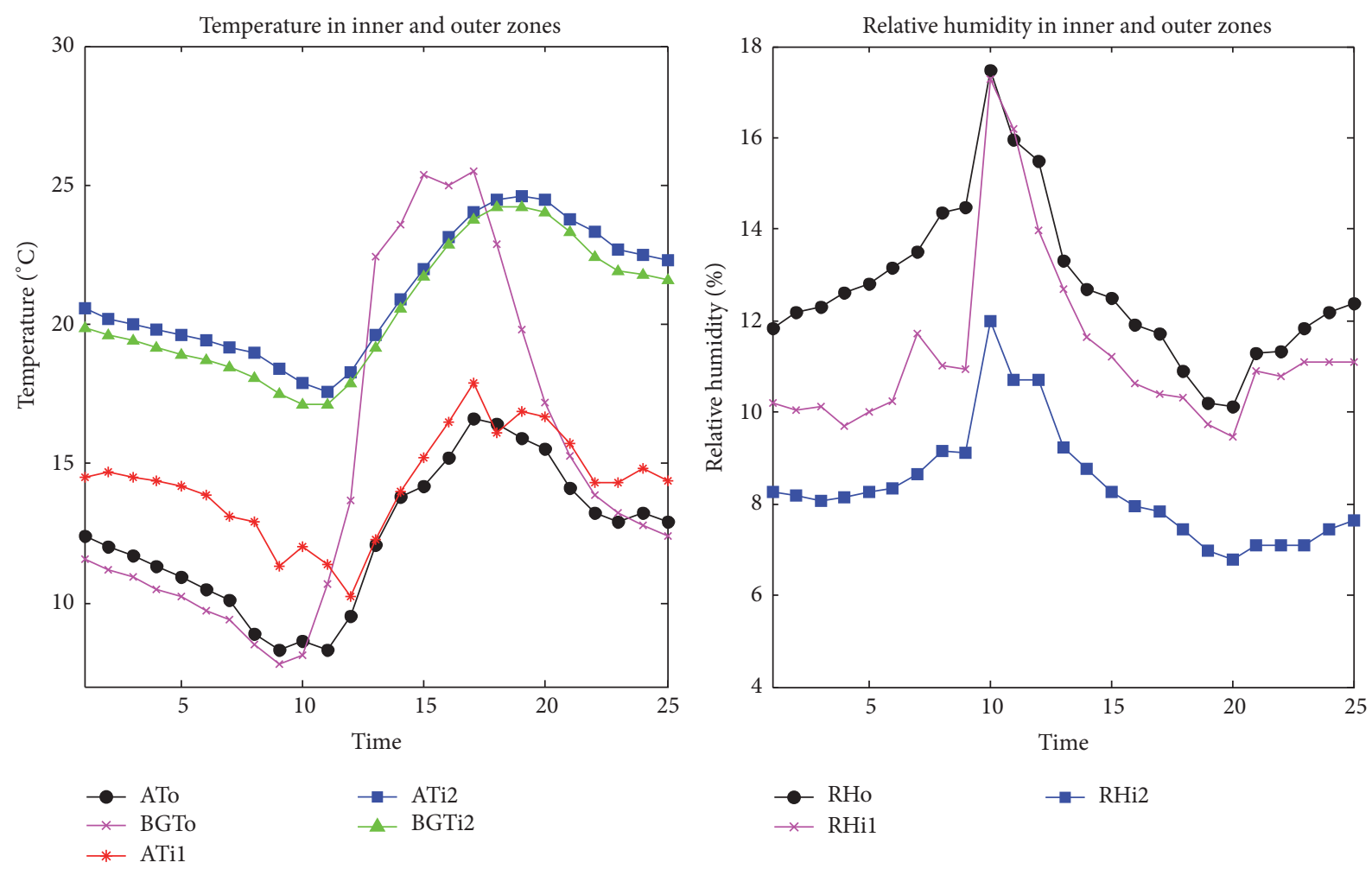

FIgURE 7: Comparison of the thermal environment in the inner and outer zones.

The difference of air temperature between inner and outer zones on the first floor is great, and the mean square error is 2.23. The reason is that the outer zone is greatly influenced by the outdoor weather conditions. On the one hand, the outside temperature at night is low, resulting in the decrease of the temperature. On the other hand, the heat gain from solar radiation through the glass facade causes the temperature to increase during the day. Besides, during the measurement it was found that there were shops in the inside part near the south glass facade, further reducing the influence of meteorological conditions on the inner zone. The average temperature of the inner zone is $1.91^{\circ} \mathrm{C}$ higher than that in the outer zone, which shows that the heat loss caused by the temperature difference is greater than the heat gain from solar radiation. Therefore, the thermodynamic parameters of south glass facade should be optimized by weighing the relationship between the heat loss and heat gain. At the same time, Figure 7 illustrates that the air temperature on the second floor is significantly higher than that on the first floor with the temperature difference within $5.4 \sim 9^{\circ} \mathrm{C}$ and the average value of $6.86^{\circ} \mathrm{C}$, indicating that temperature difference exists on the vertical direction in the terminal, which will be analyzed below.

In terms of relative humidity, the variation is opposite to that of the temperature, and its value is less than $30 \%$, showing that the indoor air is dry. So humidifying measures should be taken to improve the thermal comfort in the terminal.

4.3. The Distribution of Temperature and Relative Humidity on the Vertical Direction. Figure 8 shows that the distribution of the maximum, minimum, and mean value of temperature and relative humidity is dispersal, indicating that the temperature and relative humidity distribution on the vertical direction is uneven. However, the variation of the maximum temperature difference on the vertical direction is small, with the mean of $10.78^{\circ} \mathrm{C}$. The variation trend of the maximum, minimum, and average value is consistent with that of the ambient temperature, lagging for about $1 \mathrm{~h}$.

In order to further study the distribution characteristics of temperature and relative humidity on the vertical direction, temperature and relative humidity on the vertical direction at 0:00, 6:00, 12:00, and 18:00 are presented and analyzed, as shown in Figure 9.

The distribution of the temperature and relative humidity on the vertical direction in the terminal is not uniform, as shown in Figure 9, and there is an obvious stratification, roughly divided into three layers, the one between the ground and the height of $2.5 \mathrm{~m}$ as the first layer, the one between the height of $3.5 \mathrm{~m}$ and $8.5 \mathrm{~m}$ as the second layer, and the one between the height of $10 \mathrm{~m}$ and $13 \mathrm{~m}$ as the third one, which is related to the architectural construction of the terminal, where the area below $3.5 \mathrm{~m}$ is the first floor, $3.5 \sim 8.5 \mathrm{~m}$ the second floor, and $8.5 \mathrm{~m}$ above the part between the roof for the second floor and the terminal roof. Temperature rises with the increase of height, since the hot air density is smaller in the upper part, while the cold air is denser to sink. Thus, in order to achieve a comfortable temperature for the staff activity, the upper part, nonactivity zone, needs a higher temperature, which will add the terminal's thermal load and produce unnecessary heat loss. Therefore, terminals with 

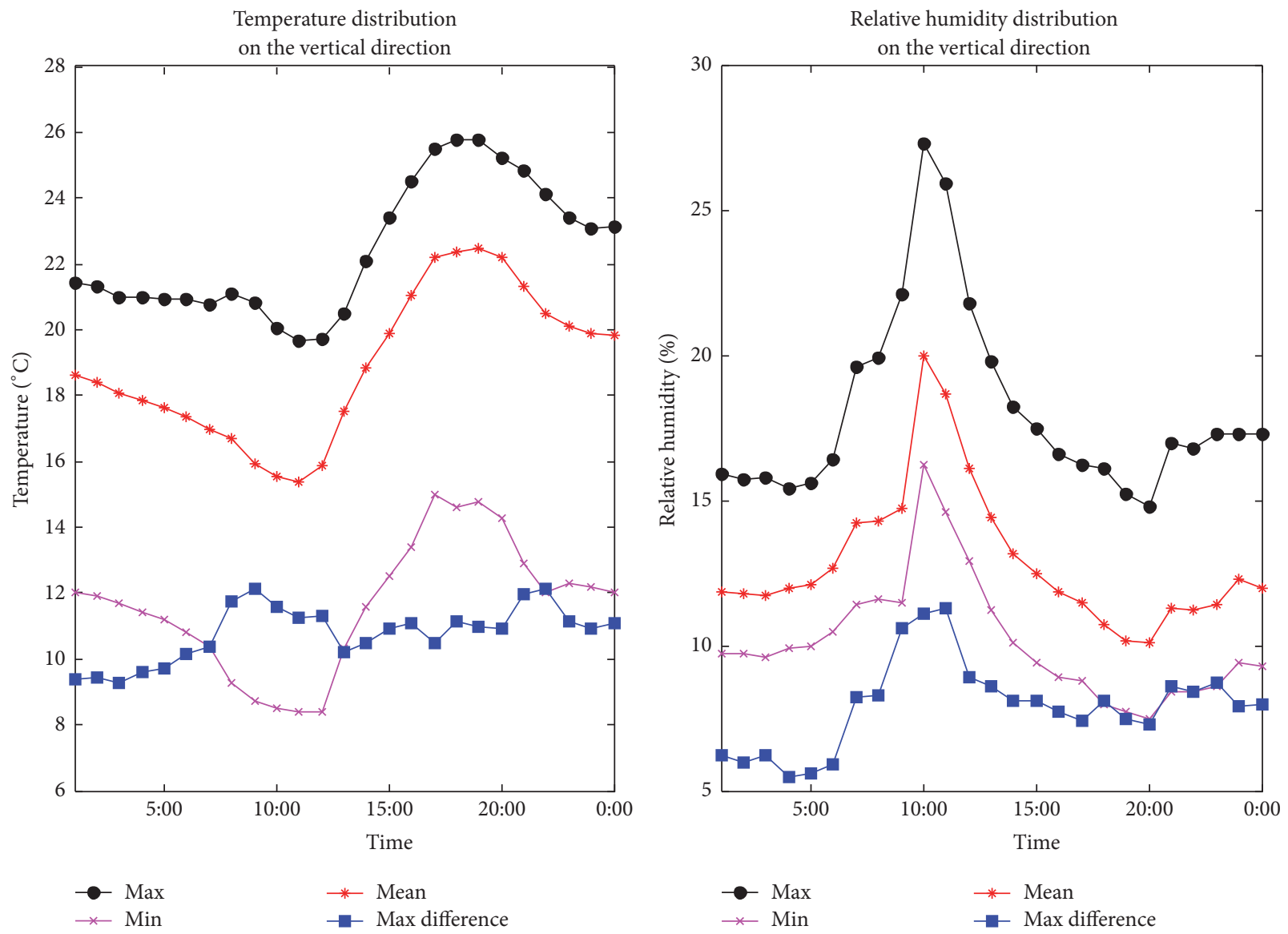

FIGURE 8: Maximum, minimum, and mean value of temperature and relative humidity on the vertical direction.
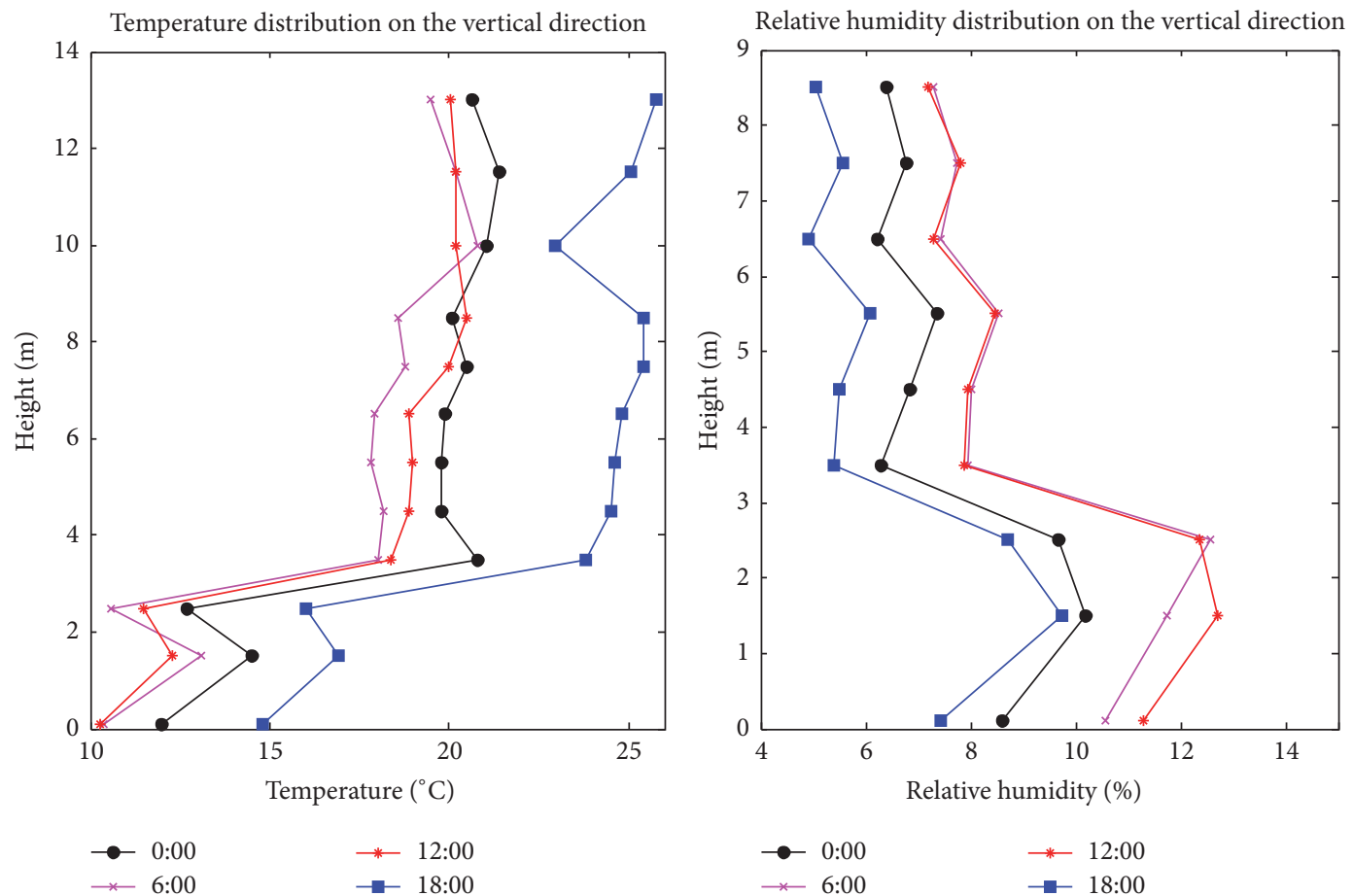

Figure 9: Distribution of temperature and humidity on the vertical direction. 


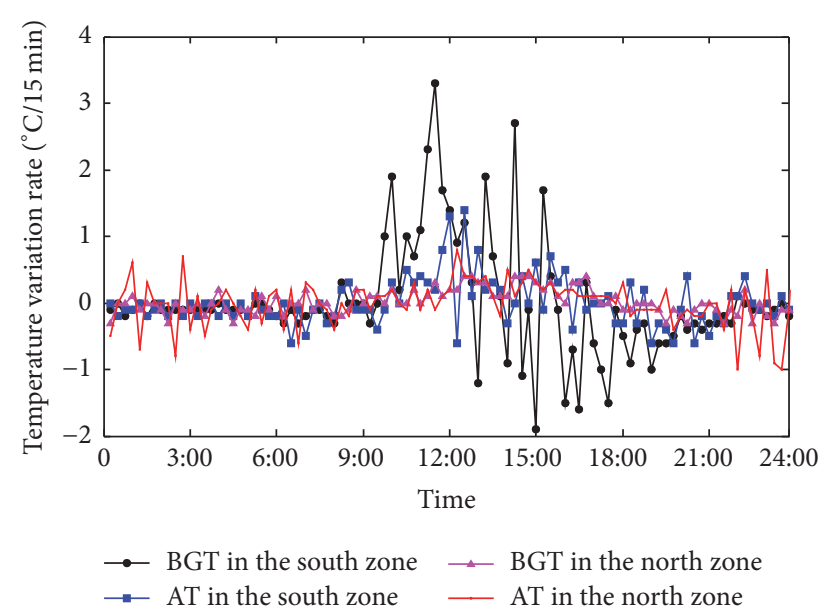

FIGURE 10: Comparison of the thermal environment in the south and north zones.

all-air heating system in Tibet Plateau should strengthen the roof insulation.

ISO7730 recommends that when the temperature within the range of $0.1 \sim 1.1 \mathrm{~m}$ above the ground is less than $3 \mathrm{k}$, it will not cause local thermal discomfort of human body [13]. On the first floor, the time when the temperature difference within the scope of $0.1 \sim 1.1 \mathrm{~m}$ on the vertical direction is more than $3^{\circ} \mathrm{C}$, which is $3.1^{\circ} \mathrm{C}, 3.6^{\circ} \mathrm{C}$, and $3.1^{\circ} \mathrm{C}$ respectively, is only at 5:00, 7:00, and 15:00. On the second floor, the temperature difference within the range of $0.1 \sim 1.1 \mathrm{~m}$ on the vertical direction is less than $3^{\circ} \mathrm{C}$. Therefore, the vertical temperature difference on the whole meets the demand for comfort and cannot cause local thermal discomfort.

4.4. Comparison of the Thermal Environment in the South and the North Zones. The measuring point in the south zone is located on the first floor, while that in the north zone is located on the second floor. Besides, as is shown in Figure 9, temperature stratification exists on the vertical direction. Therefore, only the stability of the thermal environment in the north and south zone is compared. The variation rate of black globe temperature (BGT) and air temperature (AT) in the north and south zone every $15 \mathrm{~min}$ is calculated, as shown in Figure 10.

It can been seen in Figure 10 that the variation rate of black globe temperature and air temperature in the north zone is stable, basically within \pm 0.5 , and the average absolute value is 0.27 and 0.14 , respectively, indicating that the thermal environment is stable, while the absolute value of the variation rate of black globe temperature and air temperature in the south area suddenly increases from 10:00 to 19:00, especially the former, illustrating that the black globe temperature and air temperature change greatly during this period, especially black globe temperature, which is in line with the time for the appearance of the solar radiation. As the solar radiation in Lhasa is stronger, its influence on the thermal environment in the north and south zones is significantly different. Therefore, asymmetric design should be adopted for thermal parameters of the glass facade in the north and south zones [14, 15]. For the south zone, the heat gain from solar radiation and heat loss caused by temperature difference should be weighed to maximize the net heat, while for the north zone, thermal insulation should be strengthened to minimize the thermal load. On the other hand, solar radiation in Lhasa is much higher than that in the plain region, so orientation correction coefficients are certainly different from that for the plain region. Therefore, the orientation correction should be conducted according to dynamic load simulation [4].

In terms of thermal comfort, ASHARE55-2004 standard points out to the fact that, within the scope of comfort, the permissible variation range of periodic operative temperature is below $1.1^{\circ} \mathrm{C} / 15 \mathrm{~min}$ [16]. As is shown in Figure 10, the variation rate of the black globe temperature in the north zone meets the demand of comfort, while being influenced by solar radiation, the variation rate of the black globe temperature in the south zone during the period from 10:00 to 19:00 is higher than $1.1^{\circ} \mathrm{C} / 15 \mathrm{~min}$, not meeting the requirements of comfort.

Black globe temperature is the comprehensive reflection of human thermal sensation with the effect of convection with the air and radiation with the inner surface of building envelope. Therefore, in terms of the regulation of the thermal environment in the south zone, the influence of solar radiation on the black globe temperature and PMV should be studied. Feed-forward or predictive control [17] based on solar radiation should be developed, adopting black globe temperature or PMV as the control target. Solar radiation has an effect on neutral temperature of the human body, which will become lower when exposed to solar radiation [18]. Therefore, feed-forward or predictive control based on solar radiation with variable set point should be developed, in order to overcome the hysteresis of heating systems.

\subsection{The Inner Surface Temperature of the Building Envelope.} Human thermal sensation is comprehensively influenced by the temperature of indoor air and inner surface of building envelope. Human bodies exchange heat with indoor air by convection and with building envelopes and indoor objects by thermal radiation. Therefore, the inner surface temperature of building envelopes is an important part of the indoor thermal environment, which was measured with an infrared gun from 8:00 to 20:00, including the inner surface temperature of south glass facade (SGF), east glass facade (EGF), west glass facade (WGF), south wall (SW), east wall (EW), west wall (WW), ground on the 1st floor (G1), ground on the 2st floor (G2), roof 1 (R1), and roof 2 (R2), as shown in Figure 11, in which roof 1 is the main part of the roof and roof 2 is the part for natural light, made of polycarbonate.

It is illustrated in Figure 11 that the temperature of the roof, the south glass facade, and the inner surface of south wall changes drastically, which is mainly caused by solar radiation, while the variation of the other inner surface temperature is similar to each other. The average temperature of each inner surface follows the order from high to low: roof $>$ ground on the second floor $>$ east wall $=$ south wall $>$ south glass curtain wall $>$ west wall $=$ ground on the first floor, in which the east wall is the interior wall between terminal 1 and terminal 2. The south wall and the west wall are both outside wall, with the same influence of convection and long-wave 


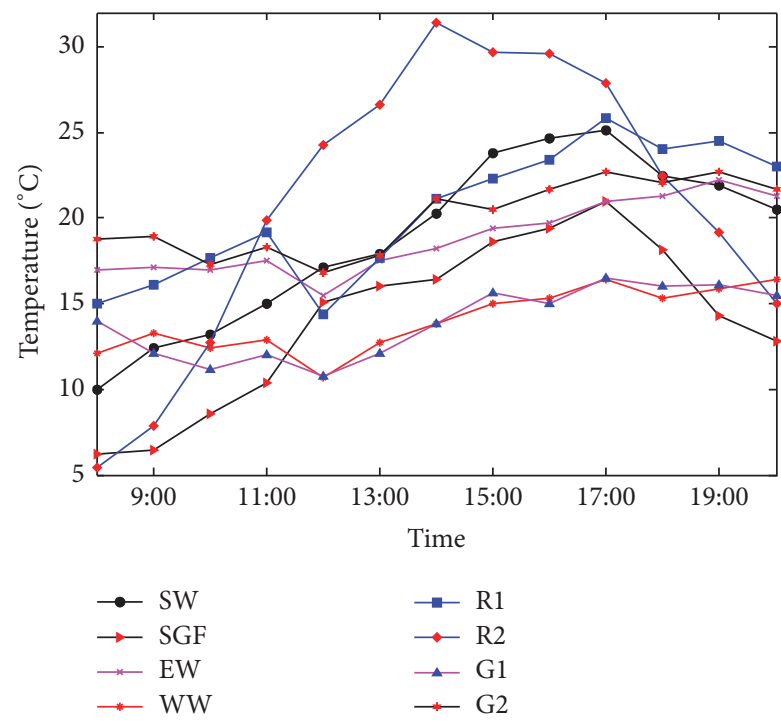

(a)

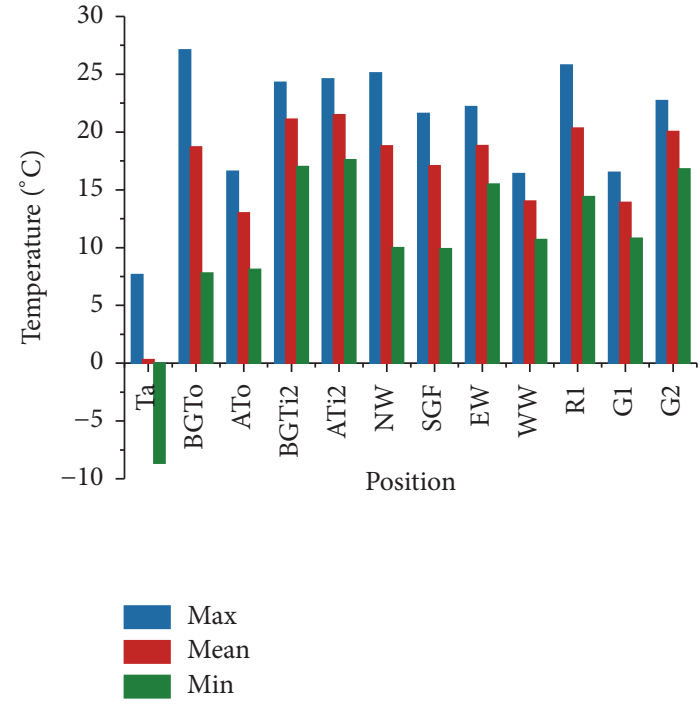

(b)

FIGURE 11: The inner surface temperature of the building envelope: (a) dynamic variation; (b) statistical characteristics.

radiation heat transfer. However, the former is $4.8^{\circ} \mathrm{C}$ higher than the latter, indicating that the influence of solar radiation on the building envelope with different orientations is significantly different. Therefore, thermal parameters of building envelopes should be optimized by weighing the relationship between the heat gain from solar radiation and heat loss caused by temperature difference. For the south glass facade asymmetric insulation should be adopted [14], in order to make full use of solar energy for passive heating. On the other hand, the terminal's orientation correction factor in this region must be different from that in the plains, which should be corrected in Tibet Plateau. Since the east wall is the interior wall, its average temperature is $4.8^{\circ} \mathrm{C}$ higher than the west wall, revealing that outdoor meteorological condition has a great influence on the west wall. So its thermal insulation should be strengthened. ASHRAE standards stipulate that the acceptable scope of the floor temperature is between 19 and $29^{\circ} \mathrm{C}$. It is shown in Figure 11 that the second floor's ground temperature is within the range of $16.8 \sim 22.7^{\circ} \mathrm{C}$, while the first floor's ground temperature is within $10.8 \sim 16.5^{\circ} \mathrm{C}$, indicating that the first floor's ground temperature is lower and easy to cause the feet cold.

In addition, the variation trend of the inner surface temperature of building envelopes is consistent with that of the outdoor temperature. Influenced by solar radiation, the south wall (including the south glass facade) and the roof are in line with outdoor temperature, lagging behind the solar radiation by $2.5 \mathrm{~h}$, while the west wall lags behind ambient temperature and solar radiation by $2.5 \mathrm{~h}$ and $5.5 \mathrm{~h}$, respectively, which provides the reference for the feed-forward control for the thermal environment based on outdoor weather conditions.

When the inner surface temperature of the building envelopes is lower, with great difference from the air temperature, its cold radiation can cause human thermal discomfort. A large amount of research data shows that when the average difference of the black globe temperature and indoor air temperature during the whole day is less than $4^{\circ} \mathrm{C}$ or the difference between the black globe temperature and the inner surface temperature of the building envelopes is less than $5^{\circ} \mathrm{C}$ and the difference between the indoor air temperature and the inner surface temperature of the building envelopes is less than $6^{\circ} \mathrm{C}$, the thermal environment conforms to the requirements of thermal comfort [19]. On the other hand, the indoor air exchanges heat with the wall by convection. The temperature difference between them determines the heat loss of the building envelopes. In order to study the cold radiation effect of the inner surfaces of the building envelopes in the terminal in Tibet Plateau on the human body and to find the face with the largest heat loss for the optimization of thermal parameters of the building envelopes, the temperature difference of the air temperature from the inner surface temperature of the building envelopes and the black globe temperature is calculated, as shown in Figure 12.

It is demonstrated in Figure 12 that the average temperature difference between indoor air and inner surfaces of the building envelopes is greater than zero, indicating that the building envelopes in general are surfaces of heat loss. However, the thermal process of the south wall and the ground on the second floor during this period realizes transformation. This is because the inner surface temperature rises after the absorption of solar radiation in the south wall, higher than indoor air temperature during the period from 15:00 to $17: 00$, so as to transfer heat to the indoor air and transform into the surface of heat gain. Then, with the disappearance of solar radiation, its surface temperature drops, becoming the surface of heat loss. As the ambient air temperature is minimum at dawn, the air temperature in the terminal decreases, while the surface temperature of the second floor's ground with larger heat capacity is higher 




FIGURE 12: Difference of air temperature from the inner surface temperature of the building envelope and black globe temperature.

than indoor air temperature during 8:00 9:00, leading to transferring heat to the indoor. Therefore, heat capacity of the interior wall in the terminal is of great significance to the stability of the indoor thermal environment, and the materials with larger heat capacity should be used for the interior wall.

Compared with the indoor air temperature and black globe temperature, the difference between air temperature and the inner surface temperature of the building envelopes is within the range of $2.6 \sim 9.3^{\circ} \mathrm{C}$ with the average value of $3.5^{\circ} \mathrm{C}$, which over $6^{\circ} \mathrm{C}$ is mainly the temperature difference from the inner surface of the west wall. The difference between the air temperature and the black globe temperature is within the range of $0.2 \sim 0.9^{\circ} \mathrm{C}$, indicating that the inner surface temperature of the building envelopes is slightly low, basically meeting the requirements of thermal comfort. Only the difference between the inner surface temperature of the west wall and the air temperature is over the comfort standard, causing obvious sense of cold radiation. Therefore, the west wall is the wall with the greatest loss of heat, whose thermal insulation should be strengthened. Olesen [20] proposed that the optimal surface temperature difference is within $5 \sim 10^{\circ} \mathrm{C}$. The temperature difference between the inner surfaces of the terminal envelopes is within the range of $3.7 \sim 9.4^{\circ} \mathrm{C}$ with the average value of $7.3^{\circ} \mathrm{C}$, illustrating that asymmetric thermal radiation exists in the terminal.

4.6. PME-PPD Indexes. Predicted Mean Vote (PMV) and Predicted Percentage of Dissatisfied (PPD) are two general international indexes for indoor thermal environment evaluation put forward by Professor Fanger in Denmark. PMV index represents thermal sensation of most people for the same the indoor environment, which is related to seven factors including air temperature, air humidity, air velocity, clothing thermal resistance, human metabolism, the type of work that people are engaged in, and mean radiation

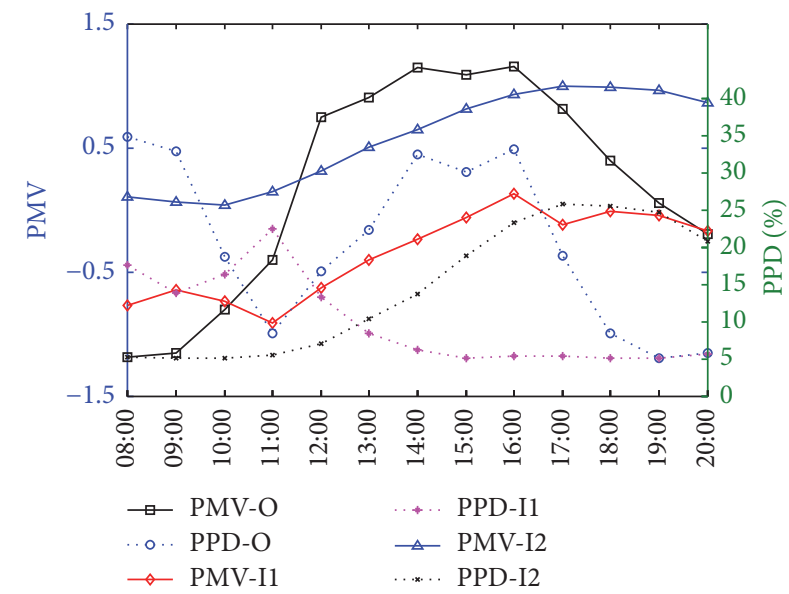

FIgURE 13: Comparison of PMV-PPD in the inner and outer zones.

temperature. PPD index is expressed as the percentage of dissatisfaction for thermal environment, related to PMV.

PMV-PPD index is used to evaluate the thermal environment in the inner and outer zones in this section, in order to compare the differences. Calculation is realized by MATLAB according to the PMV-PPD calculation formula. In order to facilitate the calculation, the following assumptions are made for the calculation process:

(1) The passengers and staff in the terminal are considered to be engaged in light physical activities, and the corresponding metabolism rate [21] is $69.78 \mathrm{~W} / \mathrm{m}^{2}$.

(2) The basic thermal insulation of the clothing of passengers and staff in the terminal is assumed to be 2.0 clo [22].

(3) The mechanical power is 0.

(4) Field measurement indicates that the indoor air velocity is extremely low. However, the indoor air velocity is required within $0.1 \mathrm{~m} / \mathrm{s} \sim 1 \mathrm{~m} / \mathrm{s}$ for PMV calculation. Then the air velocity within the terminal is assumed to be $0.15 \mathrm{~m} / \mathrm{s}$ [23].

(5) The Mean Radiant Temperature (MRT) can be approximately calculated according to the following formula [24]:

$$
\text { MRT }=\frac{\sum A_{n} T_{n}}{\sum A_{n}} .
$$

Curve PMV-O and curve PPD-O in Figure 13 represent the variation of PMV and PPD in the outer zone during the measurement, respectively. Similarly, curve PMV-I1 and curve PPD-I1 correspond to the variation of PMV and PPD in the inner zone on the ground floor, with curve PMV-I2 and curve PPD-I2 corresponding to that on the second floor. It can be seen in Figure 13 that PMV in the outer zone varies the most drastically, the reason for which is that the outer zone is affected by the outdoor weather conditions, in accordance with the most drastic variation of black globe temperature in Figure 7. Since the black globe temperature and the air 
TABLE 2: Statistics of PMV in the inner and outer zones.

\begin{tabular}{lccc}
\hline Parameters & \multicolumn{2}{c}{ Statistics } & \multicolumn{2}{c}{$\begin{array}{c}\text { In the inner zone on the second } \\
\text { floor }\end{array}$} \\
\hline Maximum & 1.155 & In the inner zone on the first floor & 0.127 \\
Minimum & -1.190 & -0.909 & 0.992 \\
Mean & -0.3 & -0.356 & 0.035 \\
Mean square error & 0.837 & 0.330 & 0.565 \\
\hline
\end{tabular}

temperature on the second floor are higher than those on the first floor, PMV in the inner zone on the second floor is higher than that on the first floor, as shown in Figure 13. The variation range, mean value, and mean square error of PMV in the outer zone and inner zone on the first and second floor are shown in Table 2, illustrating that the difference of the mean value between inner zone and outer zone on the first floor is not great, while the mean square error in the outer zone is much higher than that in the inner zone. In addition, the mean square error for the inner zone on the first and second floor has little difference.

On the other hand, PPD in the outer zone shows the most drastic variation, generally higher than that in the inner zone, which illustrates that the outer zone has poorer thermal comfort. PPD in the inner zone on the second floor from 8:00 to 13:00 is lower than that on the first floor, duo to the lower temperature on the first floor caused by the lower ambient temperature during this period of time, leading to the lower PMV and slightly cool sense. From 13:00 to 20:00, PPD on the second floor is higher than that on the first floor. The reason is that with the rise of the ambient temperature the heat load decreases and the temperature rises, leading to higher PMV. ISO 7730 standard stipulates that PPD less than $10 \%$ is taken as the design standard: that is, the thermal environment that more than $90 \%$ of the people are satisfied with is regarded as the thermal comfort environment, of which the corresponding PMV is within the range of $-0.5 \sim$ +0.5 . However, in view of the actual economic condition in China, the standard value recommended by ISO 7730 is extended to PPD less than $20 \%$ as the design basis. Figure 13 indicates that, except for 11:00, PPD in the inner zone on the first floor during the rest of the time is below $20 \%$. PPD on the second floor during 16:00 20:00 is higher than $20 \%$, accounting for $38.46 \%$ of the total time, due to the slight warmth influenced by the high temperature during this period. However, PPD in the outer zone during 8:00 9:00 and 13:00 16:00 is higher than 20\%, accounting for $46.15 \%$ of the total time, which is mainly caused by the slight cooling and warmth influenced by the ambient temperature and solar radiation, respectively. The average PPD in the outer zone and inner zone on the first and that in the inner zone on second floor are $20.56 \%, 9.96 \%$, and $14.65 \%$, respectively.

\section{Conclusion}

A field measurement is conducted for the indoor thermal environment of terminal 2 of Lhasa Gonggar Airport with central air conditioning for heating in this paper, with the differences of the thermal environment in the north and the south zone and in the inner and outer zone, the inner surface temperature of building envelopes, and the distribution of temperature and relative humidity on the vertical direction comprehensively analyzed, making the following conclusions:

(1) The influence of solar radiation on the north and south zones in the terminal is significantly different. Influenced by direct solar radiation, the variation of the thermal environment in the south zone is more drastic, especially black globe temperature, the fluctuation of which can cause thermal discomfort, while the northern is only affected by diffuse radiation. Therefore, the heat load calculation should be corrected according to the orientations. In addition, the correction coefficients are different from that in the plain, which shall be corrected for Tibet Plateau. The thermal parameters of the north and south glass facade should take asymmetrical design. The relationship between insulation and heat gain from solar radiation should be weighed for the south glass facade in order to make use of solar energy for passive heating to the greatest extent, while for the north glass facade thermal insulation should be given priority. In the aspect of control strategy, feed-forward or predictive control based on solar radiation should be developed for the south, to overcome the hysteresis of heating systems.

(2) There are great differences between the thermal environment in the inner and outer zones in the terminal. The latter changes drastically, whose black globe temperature and air temperature have very great differences, illustrating that the outer zone is greatly influenced by solar radiation. Therefore, on the one hand, the ground of the terminal should use materials with larger absorption rate and heat capacity, in order to make full use of solar energy and make the thermal environment stable. On the other hand, the inside area of the south glass facade should have no shading, in order to make full use of solar energy.

(3) The inner surface temperature of building envelopes is higher. Except for the west wall, the average temperature difference between air and the rest of the building envelopes' inner surface is less than $4^{\circ} \mathrm{C}$. The west wall is the wall with the greatest loss of heat, which 
can cause cold radiation feeling. Thus, its thermal insulation should be enhanced. The influence of solar radiation on the building envelopes with different orientations is significantly different. Optimization design should be made for thermal parameters of building envelopes with different orientations. Asymmetric thermal insulation should be adopted. The temperature difference between the inner surfaces of the building envelopes is greater, leading to thermal discomfort caused by asymmetric radiation.

(4) The terminal with all-air heating system has temperature and humidity stratification on the vertical direction. Temperature on the top is higher, causing unnecessary heat loss. Thus, the thermal insulation of the roof should be enhanced. The vertical temperature difference will not cause local thermal discomfort.

(5) PMV-PPD indexes indicate that the variation of PMV-PPD indexes in the outer zone is the most drastic, leading to the worst thermal comfort, while it is optimal in the inner zone on the first floor, basically meeting the requirement of thermal comfort. Compared with the first floor, the thermal environment on the second floor has poorer thermal comfort, mainly caused by high temperature.

\section{Conflicts of Interest}

The authors declare that they have no conflicts of interest.

\section{Acknowledgments}

The authors would like to thank the leaders and engineers of Lhasa Gonggar Airport and students from Chongqing University for their support on site measurements. This research is supported by the National Natural Science Foundation of China (no. 51478058) and 111 Project (no. B13041).

\section{References}

[1] D. Wang, Y. Liu, Y. Wang, and J. Liu, "Measurement and evaluation of indoor thermal environment of residential buildings in Lhasa in winter," Building Science, vol. 27, no. 12, pp. 20-24, 2011.

[2] D. Wang, Y. Liu, J. Liu, and Y. Akashi, "Measurement study on influence factors of building indoor thermal environment in winter in Lhasa," Building Science, vol. 26, no. 8, pp. 23-26, 2010.

[3] D. Wang, Y. Liu, J. Liu, B. Wang, and H. Chen, "Measuring study of heating performance of passive solar house with Trombe wall in Qinghai-Tibet plateau," Acta Energiae Solaris Sinica, vol. 34, no. 10, pp. 1823-1828, 2013.

[4] X. Zhu, L. Yang, J. Liu, and R. Wang, "Correction factor for heat transfer coefficient of city building envelope in Tibet autonomous region," Journal of Tsinghua University, vol. 48, no. 9, pp. 1381-1384, 2008.

[5] L. Huang and Y. Leng, "Field study of winter indoor thermal environment of traditional dwelling in Nyingchi, Tibet," South Architecture, vol. 1, no. 12, pp. 92-96, 2012.

[6] C. A. Balaras, E. Dascalaki, A. Gaglia, and K. Droutsa, "Energy conservation potential, HVAC installations and operational issues in Hellenic airports," Energy and Buildings, vol. 35, no. 11, pp. 1105-1120, 2003.

[7] A. Kotopouleas and M. Nikolopoulou, "Understanding thermal comfort conditions in airport terminal buildings," in Proceedings of the 8th Windsor Conference: Counting the Cost of Comfort in a Changing World, pp. 10-13, Cumberland Lodge, Windsor, UK, April 2014.

[8] J. E. Ramis and E. A. Santos, "The impact of thermal comfort in the perceived level of service and energy costs of three Brazilian airports," Journal of Transport Literature, vol. 7, no. 2, pp. 192206, 2013.

[9] Z. Wang, H. Zhao, B. Lin, Y. Zhu, Q. Ouyang, and J. Yu, "Investigation of indoor environment quality of Chinese largehub airport terminal buildings through longitudinal field measurement and subjective survey," Building and Environment, vol. 94, pp. 593-605, 2015.

[10] Y. Liu, J. Liu, L. Yang, and J. Li, "Measureing study of passive solar house for traditional dwelling building in Lhasa area," Acta Energiae Solaris Sinica, vol. 29, no. 4, pp. 391-394, 2008.

[11] W. Wang, L. Liu, S. Shen, D. Wu, and J. Du, "Distributed modeling of global solar radiation over rugged terrain of Tibet," in Proceedings of the Summary of the 17th China Remote Sensing Conference, 2010.

[12] L. Chang, Applied Research on Optimization Method of District Heating Source Schemes in Lhasa, Chongqing University, Chongqing, China, 2014.

[13] ISO EN 7730, Moderate Thermal Environments-determination of the PMV and PPD Indices and Specification of the Conditions for Thermal Comfort, International Standards Organization, Geneva, Switzerland, 1994.

[14] E. Li, J. Liu, and W. Zhang, "Projections of extreme temperature events in Chongqing for the 21st century," Journal of Southwest University (Natural Science Edition), vol. 27, no. 4, pp. 36-41, 2011.

[15] G. Sang and J. Liu, "Study of energy efficiency envelope configuration of heating residential buildings in solar radiation zone," Acta Energiae Solaris Sinica, vol. 32, no. 3, pp. 416-422, 2011.

[16] X. Sui and X. Zhang, "Analysis of operating conditions and indoor thermal environment of floor cooling system," Railway Standard Design, supplement 2, pp. 28-31, 2010.

[17] X. Lin, R. Wang, M. Duan, and Z. Wang, "Hourly heating load prediction of radiant floor heating systems based on BP neutral network," $H V \mho A C$, vol. 41, no. 12, pp. 95-98, 2011.

[18] G. Feng, R. Liang, J. Ning, Y. Gao, and Z. Guo, “The analysis of the impact of solar radiation through windows on human thermal comfort," Journal of Shenyang Jianzhu University (Natural Science), vol. 23, no. 5, pp. 790-793, 2007.

[19] X. Zhang, B. Dong, Y. Ma, and Y. Pan, "Studying about the influence of indoor bubble globe temperature to room thermal comfortable," Building Energy \& Environment, vol. 26, no. 5, pp. 79-81, 2007.

[20] B. W. Olesen, "Possibilities and limitations of radiant floor cooling," in Proceedings of the ASHRAE Winter Meeting 1997, pp. 42-48, January 1997.

[21] Z. Wang, Z. Zhang, and L. Lian, "Discussion of thermal comfort indices and design indoor temperature for winter heating," HV\&AC, vol. 32, no. 2, pp. 26-28, 2002.

[22] L. Huang, B. Lan, and Dawazhaxi, "Subjective thermal comfort evaluation study of Lhasa traditional building," Huazhong Architecture, vol. 11, pp. 67-70, 2012. 
[23] F. Wang, J. Chen, and J. Liu, "Evaluation and analysis on winter indoor thermal environment of dwellings in river valley in the middle part of Nujiang," Building Science, vol. 27, no. 10, pp. 4046, 2011.

[24] R. Hu, W. Li, W. He, and J. Liu, "Study on winter indoor thermal environment of the folk houses in Qinling Mountains," Acta Energiae Solaris Sinica, vol. 32, no. 2, pp. 171-174, 2011. 


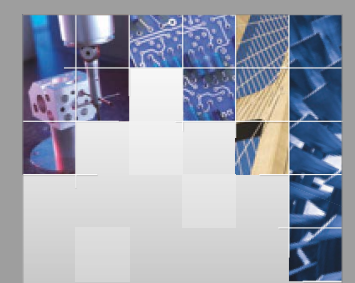

\section{Enfincering}
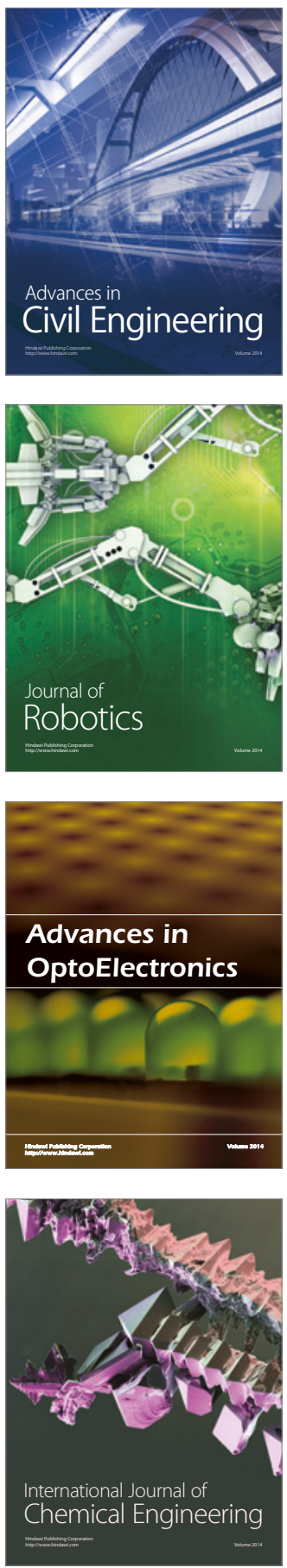

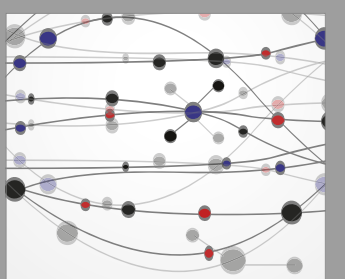

The Scientific World Journal

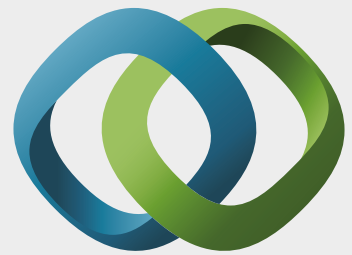

\section{Hindawi}

Submit your manuscripts at

https://www.hindawi.com
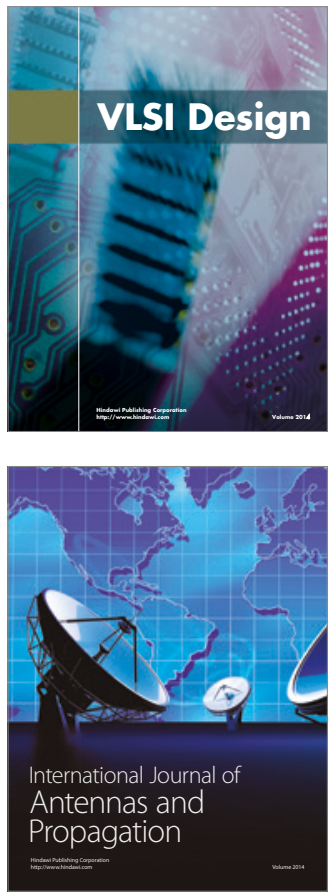

\section{Rotating}

Machinery

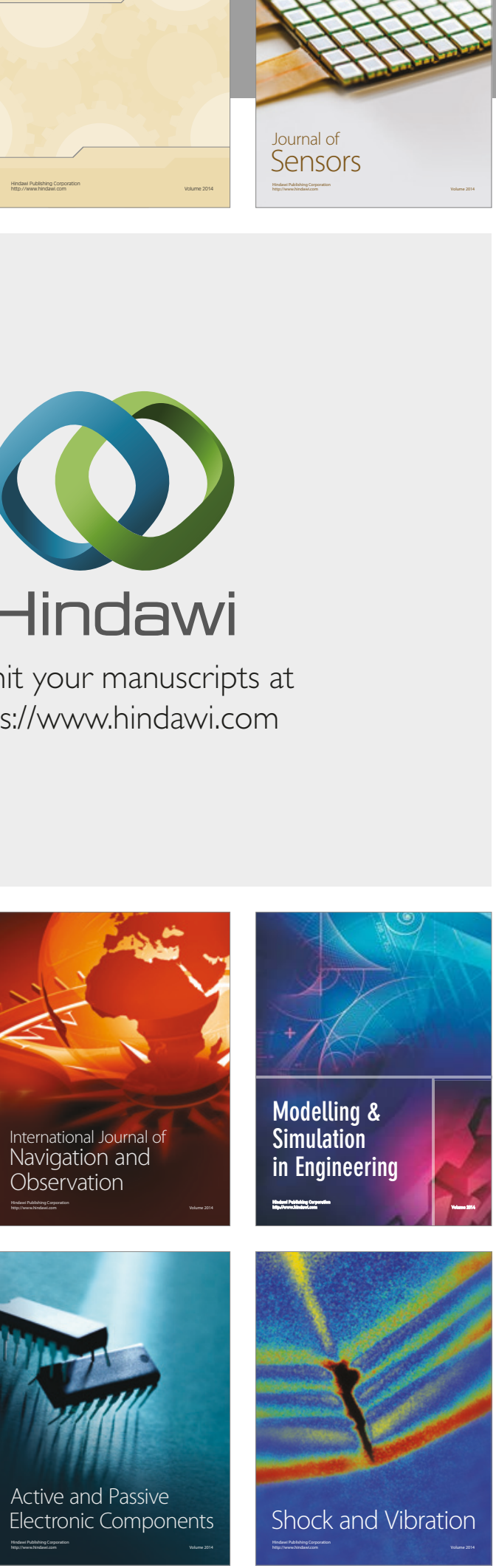
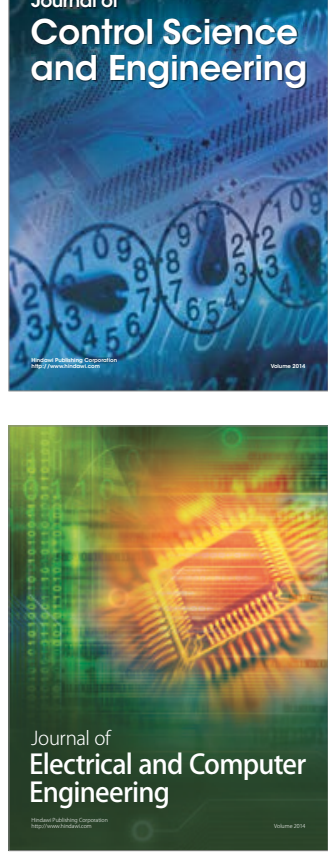

Distributed

Journal of

Control Science

and Engineering
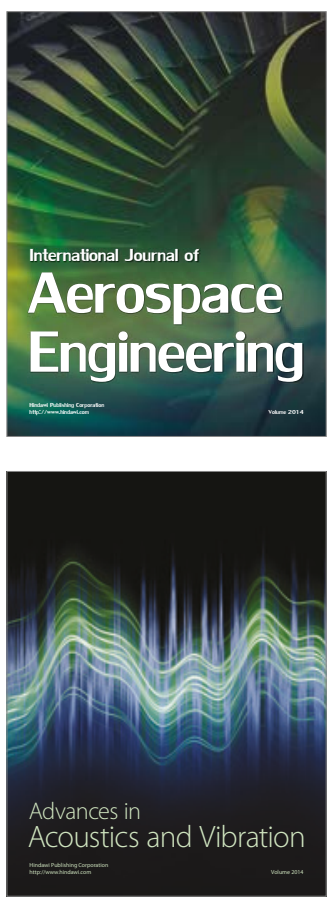

Sensor Networks 